\title{
LA CONSTRUCCIÓN DE POLÍTICAS TURÍSTICAS ORIENTADAS A LOS SECTORES MEDIOS DURANTE EL PRIMER PERONISMO: ARGENTINA 1946-1955*
}

Recebido em: 17/09/2016

Aceito em: 14/02/2017

Melina Piglia

Elisa Pastoriza

Universidad Nacional de Mar del Plata

Mar del Plata - Argentina

RESUMEN: En el marco general de los estudios de las políticas públicas durante el primer peronismo (Argentina 1946-1955), el presente trabajo pretende abordar aspectos descuidados de las políticas turísticas, desde una perspectiva de historia social. El artículo sostiene que, junto a las más conocidas transformaciones producidas en el campo del turismo obrero y el turismo social, se puede advertir durante el período peronista la puesta en marcha de políticas turísticas orientadas al turismo de los sectores medios. Ellas redundaron en inversiones en importantes obras de infraestructura, como caminos, transportes, balnearios y hotelería y en una creciente integración del territorio nacional.

PALABRAS CLAVE: Actividades Recreativas. Turismo. Clase Social.

\section{TOURISM POLICIES AIMED AT THE MIDDLE CLASSES DURING THE FIRST PERONISM: ARGENTINA 1946-1955}

ABSTRACT: In the general context of public policy studies during the first Peronism (Argentina 1946-1955) and from a perspective of Social History, this paper aims to address neglected aspects of tourism policies. The article argues that, apart from the better known transformations in the field of tourism workers and social tourism, there can be noticed during the Peronist period an emergence of tourism policies tourist oriented towars middle sectors. They resulted in important investments in infrastructure, such as roads, transportation, seaside resorts and hotels and a growing integration of National territory.

KEYWORDS: Leisure Activities. Tourism. Social Class. 


\section{Introducción}

El turismo es una práctica moderna, que implica un desplazamiento con fines recreativos por un período acotado de tiempo. Se distingue del veraneo aristocrático porque supone como parte constitutiva la otra cara de la moneda, el trabajo. Se asocia por lo tanto a la generalización de las vacaciones en los usos de los profesionales liberales y los sectores medios de comerciantes o industriales primero y entre los asalariados después, a medida que fue extendiéndose el beneficio de las vacaciones pagas. Es un fenómeno que involucró inicialmente a diferentes grupos medios y que se consolidó con el turismo masivo de sol y playa posterior a la Segunda Guerra Mundial.

Los estudios históricos sobre el turismo, de relevante desarrollo en las últimas décadas, han permitido reflexionar de manera novedosa sobre las percepciones e imaginarios sociales (e.g. CORBIN, 1993), las políticas públicas (e.g. BARANOWSKY, 2007), la historia urbana y la cultura popular (WALTON, 1983). En Latinoamérica los estudios son más escasos y la perspectiva dominante ha sido, en general, la de la historia de las localidades turísticas y balnearios (DA CUNHA y CAMPODÓNICO, 2012; PASTORIZA, 1999a; 2003) aunque en los últimos años algunos trabajos han abordado el estudio de las políticas turísticas (e.g. PASTORIZA, 2011; TORRE y PASTORIZA, 2002; PIGLIA, 2011).

Desde esta perspectiva, en la Argentina de los años veinte, el turismo surge ligado a la movilidad social ascendente y al deseo de los sectores medios de imitar las prestigiosas prácticas recreativas de las élites), a la expansión del tiempo libre disponible y a la difusión de nuevos valores y prácticas (PASTORIZA, 2011). La Argentina de la primera mitad del siglo XX presenta algunas peculiaridades que la recortan del contexto latinoamericano. A consecuencia de su -por varias décadas muy 
exitosa- inserción en el mercado mundial como exportadora de carnes y cereales y de un acelerado proceso de crecimiento económico, su población se había multiplicado con la masiva llegada de inmigrantes, experimentando un temprano proceso de urbanización. ${ }^{1}$ La actividad agroexportadora argentina generó una considerable riqueza, producto de las ventajas comparativas que ofrecía la extraordinaria fertilidad de la llanura pampeana y de los procesos de producción llevados a cabo (GERCHUNOFF y LLACH, 1998). Por sus características, posibilitó además una cierta distribución de esa riqueza (en el contexto de desigualdad capitalista), que condujo a la expansión de las ciudades del Litoral, al engrosamiento de los sectores medios y la modernización cultural ${ }^{2}$. En ese marco, emergió un estado en busca del progreso, cuyos principales pilares fueron constituidos por la inmigración, la educación y el ingreso de capitales y tecnología. Asimismo, se neutralizó el rol de la iglesia, restándole el control de los momentos cruciales en la vida de los hombres -nacimiento, casamiento y muerte-, con la Ley de Registro y Matrimonio Civil. Los otros instrumentos para nacionalizar a los hijos de los inmigrantes fueron las leyes de educación primaria laica, gratuita y obligatoria, y la de Servicio Militar Obligatorio, las grandes palancas igualitarias. Una señal de esta modernización, fue la rápida difusión del automóvil en el país: en los años veinte y treinta la Argentina era el país de Latinoamérica con más automóviles (aunque uno de los menos poblados) y tenía una relación entre automóviles y población similar a la de Francia (PIGLIA, 2014).

\footnotetext{
${ }^{1}$ El país recibió alrededor de unos seis millones de inmigrantes entre 1870 y 1930 , de los cuales la mitad se asentó finalmente en el país. Su población pasó de 1.830 .214 en 1869 a 7.903.662en 1914 y 15.893.827 en 1947. Ya desde 1914 más de la mitad de la población argentina vivía en ciudades, mientras el promedio latinoamericano para 1925 era del 25\%. (LOBATO y SURIANO, 2000).

${ }^{2}$ La actividad agroexportadora requería para realizarse de una serie amplia de infraestructuras y servicios lo que multiplicaba las oportunidades de empleo. El crecimiento de las ciudades del Litoral como Buenos Aires y Rosario ligado a esa economía, (y al consumo ostentoso de la elite terrateniente que era su principal beneficiaria), generó a su vez nuevas oportunidades para el desarrollo manufacturero, el empleo urbano y el ascenso social. El resultado fue el crecimiento de los sectores medios, que el sociólogo Gino Germani (1965) estimaba en un 30\% para 1914.
} 
El surgimiento de centros turísticos formó parte del crecimiento, de la modernización y de la movilidad social. Las prácticas de ocio de las prósperas élites, aficionadas a los lugares de recreación europeo, dieron origen desde fines del siglo XIX a la creación de villas turísticas en la costa atlántica del país y en los valles serranos de la provincia de Córdoba (PASTORIZA, 2011). Desde finales de los años veinte, en tren o en automóvil, cantidades cada vez mayores de turistas comenzaron a afluir a los antes exclusivos balnearios bonaerenses de Mar del Plata o Miramar o a las sierras de Córdoba, a la par que se ampliaban los elencos sociales que podían disfrutaban de las vacaciones y surgían nuevos lugares turísticos, como los de la Patagonia Andina, los nuevos balnearios de la costa norte o el Noroeste argentino (PASTORIZA, 2011) (FIGURA 1).

Figura 1: La red vial Argentina en 1943.

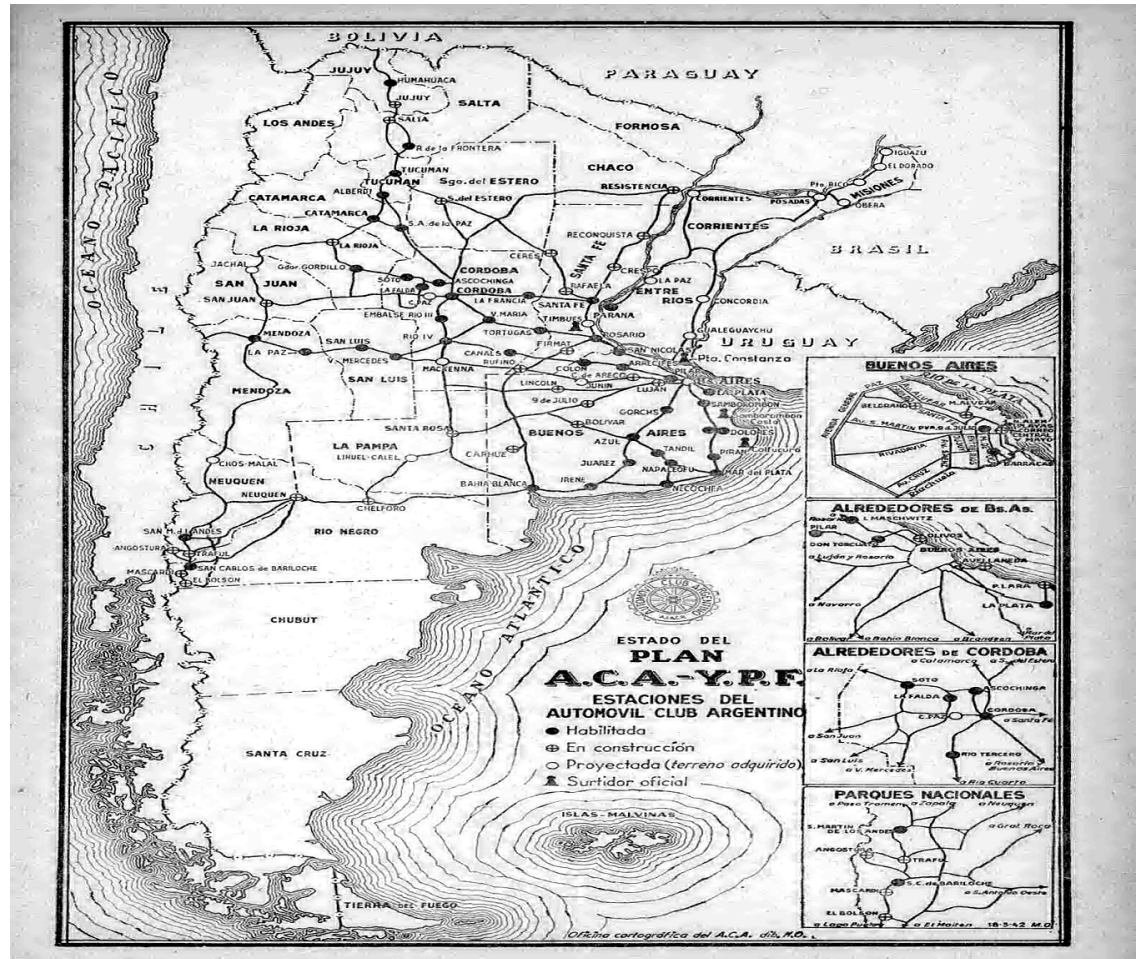

Fuente: Guía del Automóvil Club Argentino, 1943. 
El mencionado proceso de difusión del turismo implicó además una serie de construcciones simbólicas, de los lugares turísticos en tanto tales, de las prácticas y sus significados. A la vez que se difundía como práctica, el turismo fue en las primeras décadas del siglo XX construido socialmente como un asunto de bien público, resaltando sus beneficios pedagógico-patrióticos, higiénicos y/o económicos, para el individuo y para la colectividad. Estas concepciones encarnaron en el Estado en los años treinta y se tradujeron en una serie de políticas concretas -desde la creación de la Dirección de Parques Nacionales, hasta la construcción de algunas rutas de turismo- que formaron parte de en lo que podemos denominar un segundo proceso modernizador (Véase Figura 1) $)^{3}$ (PASTORIZA, 2011; PIGLIA, 2011).

Los cambios políticos asociados a la llegada de Juan Domingo Perón al poder significaron una potenciación de estos fenómenos ${ }^{4}$. Un conjunto de políticas de efectos redistributivos y de aliento al desarrollo del mercado interno ${ }^{5}$, entre otros muchos efectos, pusieron el turismo alcance de crecientes sectores sociales, incluidos los trabajadores.

En el campo académico argentino, los análisis históricos de las políticas turísticas han sido más bien escasos. En términos generales el período peronista ha capturado la mayor parte del interés y los trabajos se han concentrado, sobre todo, en las

\footnotetext{
${ }^{3}$ Se trataba de un proceso de modernización social y económica en un marco de conservadurismo político (BALLENT y GORELIK 2002; PASTORIZA 1999b)

${ }^{4}$ Miembro del grupo militar que se hizo con el gobierno argentino tras un golpe de Estado en 1943, el por entonces Coronel Perón se hizo cargo unos meses más tarde de la Secretaría de Trabajo y Previsión. Su vinculación con los sindicatos le permitió construir su propia base política y ampliar su influencia dentro del gobierno de facto, triunfando luego en las elecciones en febrero de 1946. Tras una reforma constitucional en 1949 que le habilitó un segundo mandato, fue reelecto y permaneció en la presidencia hasta el golpe de estado de 1955.

${ }_{5}^{5}$ El gobierno peronista encaró un proceso de redistribución del ingreso hacia los sectores menos favorecidos que impulsó la expansión del mercado interno y la industrialización por sustitución de importaciones . Como parte de este proceso, los salarios relaes se elevaron en más de un $60 \%$, y se amplió marcadamente su acceso a la educación, la salud, la vivienda y la recreación (TORRE y PASTORIZA, 2002).
} 
políticas de turismo social (PASTORIZA, 2008a e b; TORRE y PASTORIZA, 2002; SCARZANELLA, 1998).

Nos interesa aportar a estas cuestiones desde una perspectiva que destaca tanto los efectos de estas políticas sobre el territorio, como el lugar de los sectores medios en las políticas turísticas peronistas orientadas a extender el turismo popular. $\mathrm{Si}$, como han mostrado Juan Carlos Torre y Elisa Pastoriza, los sectores medios fueron los que en mejores condiciones estuvieron para beneficiarse de las políticas peronistas de democratización del bienestar -entre ellas el acceso al turismo (TORRE y PASTORIZA, 2002; 1999a)- en este trabajo sostendremos que el peronismo desplegó también políticas específicamente destinadas a alentar el turismo de dichos sectores sociales, por un lado porque formaban parte de ese continuo de "sectores populares" a los que se buscaba incluir y, por el otro, porque se ensayó estimular el desarrollo del turismo como industria. Lo haremos abordando algunos aspectos poco transitados de la política turística peronista, como la construcción de "hoteles nacionales", el financiamiento de segundas residencias en la costa o la construcción de caminos para el turismo en automóvil.

\section{Democratizar el Turismo: Obreros y Sectores Medios}

Durante el primer peronismo el turismo se convirtió en una política de estado. Sostenido por una serie de cambios legales que, en el verano de 1945 configuraron el primer escenario donde se desenvolvería la política turística peronista: la generalización de las vacaciones remuneradas; la creación del aguinaldo (un sueldo anual complementario) y el decreto sobre salario básico, mínimo y vital; el establecimiento por primera vez de un fondo específicamente destinado al fomento del turismo social, sobre la base de un descuento del 5\% del aguinaldo y el decreto de Personería Gremial, que 
permitió a los sindicatos fundar instituciones de previsión y asistencia social (PASTORIZA, 2008a e b; 2011). Este corpus de leyes y decretos apuntaban a uno de los objetivos explícitos del nuevo régimen: garantizar el acceso de los trabajadores al disfrute del ocio, y, en especial, al turismo.

Entre 1946 y 1950, tres líneas principales articularán esta política: el turismo sindical, que se desarrolló sobre todo en los valles cordobeses, donde los sindicatos adquirieron y construyeron hoteles y colonias de vacaciones; los planes interprovinciales de turismo social, que se realizaron en colaboración con la central nacional de trabajadores (CGT) permitieron vacacionar a unas 220.000 personas de familias trabajadoras; y los planes nacionales, mucho más modestos, que entre 1946 y 1950 estuvieron a cargo de una nueva repartición, la Administración de Parques Nacionales y Turismo (AGPT), creada sobre la base de la Dirección de Parques Nacionales (PIGLIA, 2011).

En 1950, una serie de cambios dentro del Estado peronista se expresaron a nivel institucional: la AGPT fue fracturada, y el turismo quedó escindido de la Administración de los Parques; a la vez, el turismo social nacional (y sus recursos) pasaron a la órbita de la Fundación Eva Perón (una entidad cuasi estatal creada y dirigida por la activa e influyente Primera Dama) (PASTORIZA, 2008a e b; 2011; PASTORIZA y PIGLIA, 2012). En paralelo, el II Plan Quinquenal (1953-57), consagró al turismo social y escolar como objetivos del Estado, fijando el interés en que la población conociera y se apropiara (se "sientan dueños") de la República mediante el acceso a las regiones turísticas. A la vez, se apostaba también al turismo como industria, estimulando la llegada de viajeros internacionales. Para ambos objetivos, se proponía facilitar la construcción de hoteles, hosterías y colonias, efectuando y alentando inversiones en lugares turísticos, realizando 
convenios internacionales y fomentando los deportes. Se concebía además una consolidada organización nacional del turismo asentada en la creación de una escuela de capacitación hotelera y turística, una nueva clasificación y sistema tarifario hotelero, la elaboración de una ley nacional de turismo y un sistema de inversiones e incentivos destinados a incentivar la industria privada (II PLAN QUINQUENAL, 1953).

Como veremos abajo, durante toda la década, la retórica oficial peronista hizo fuerte hincapié en la idea del acceso por parte de los obreros a prácticas y lugares antes reservados a los privilegiados, enfatizando la concepción del turismo como conquista y derecho. Sin embargo, de modo menos estridente, la política turística del peronismo también se desplegó en otros sentidos, que miraban al turismo como industria y que respondían a un objetivo de ampliación de las posibilidades recreativas de sectores medios de recursos moderados y, por lo tanto, de la ampliación del turismo popular no organizado.

\section{7-1950 - La Administración General de Parques Nacionales y Turismo: Hoteles}

\section{Nacionales}

El régimen peronista se caracterizó por una concepción del Estado como árbitro y rector en los terrenos económico y social y eso implicó, en la práctica, un avance en la centralización de las agencias públicas y una ampliación de la esfera de influencia estatal. La política turística, hasta entonces incipiente, fragmentaria y dispersa se centralizó en la AGPT bajo la consigna única de la democratización (PIGLIA, 2011). Tenía un alcance nacional, se ocupaba de organizar programas de turismo social y escolar y debía sugerir leyes que regularan la actividad en todo el país y centralizar y difundir la información sobre el turismo nacional. La nueva repartición tenía además jurisdicción sobre los parques nacionales y sobre los hoteles nacionales de turismo existentes hasta entonces: el 
lujoso Llao-Llao (en el Parque patagónico Nahuel Huapi) y el más modesto Hotel de Catamarca (provincia de Catamarca).

Abrir el turismo a nuevos viajeros implicaba, en primer lugar, acrecer y abaratar las plazas hoteleras. A través de la Administración de Parques se puso en marcha una activa política de adquisición, ampliación y construcción de hoteles y hosterías en todo el país. Así, por ejemplo, en el Parque Nahuel Huapi la repartición adquirió alojamientos, construyó un refugio en el cerro Catedral (Bariloche), campamentos para estudiantes en la península Huemul y a orillas del lago Mascardi; mientras, en el noreste del país, en el Parque Iguazú, se inició la construcción de un nuevo hotel. Retomando los proyectos aprobados y puestos parcialmente en marcha a comienzos de los años cuarenta (PIGLIA, 2012a), se terminaron entre 1947 y 1948, las obras de los hoteles de la provincia de La Rioja (Chilecito y Andalgalá) y de una hostería de Ancasti (provincia de Catamarca), y se edificó uno en la ciudad de San Luis (provincia de San Luis). Estas iniciativas prosiguieron a ritmos febriles entre 1947 y 1950, ya por fuera de los planes de los gobiernos previos, con la instalación de hoteles en la ciudad de Corrientes, en Viedma (Río Negro) y en Paso de Los Libres (Misiones). Se adquirieron además otros dos: la hostería El Molino (en Villa del Soto, Córdoba) y el de Puente del Inca (Mendoza), que pertenecía a los ferrocarriles (adquiridos por el Estado nacional en 1947) y que fue acondicionado y administrado por la Administración de Parques y Turismo durante algunos meses, para pasar en 1949 a la Fundación Eva Perón (PIGLIA, 2012a). El número total de plazas de los hoteles nacionales se triplicó entre 1945 y 1949 (MAGPT, 1949). La amplia distribución geográfica de los nuevos hoteles plasmaba de forma concreta la intención de que el turismo popular fuera un vehículo de integración 
nacional: conocer la patria, apropiársela, era un imperativo patriótico, capaz de galvanizar la identidad nacional.

Los hoteles se otorgaron en concesión a empresarios privados para su explotación, aunque por supuesto el estado se reservó la prioridad del uso y la capacidad de controlar las tarifas. Estos establecimientos se proponían como el núcleo de futuros lugares turísticos y, por lo tanto, eran la punta de lanza para alentar la inversión privada. A la vez aportaban el "alojamiento amplio y barato" para procurar darle sustento real a las vacaciones populares y a la convocatoria a conocer el país, que ahora se dirigía a todos los habitantes (MAGPT, 1947, p. 14).

La ampliación de las plazas disponibles fue reforzada además por la Ley de Crédito Hotelero (1947), que financió la construcción de hoteles privados más modestos $^{6}$. La misma ley, por otro lado, establecía una línea de créditos a intereses bajos (de entre el 3,25 y el 6\%) para financiar la compra o construcción de viviendas de veraneo, una política que favorecía directamente a los sectores medios y sobre la que volveremos más adelante (MAGPT, 1947).

A la mayor oferta y el abaratamiento del alojamiento, se sumaron mejoras en el transporte: el ferrocarril se abarató tras la estatización, avanzó al pavimentación de las rutas iniciadas durante los gobiernos conservadores y se mejoraron los servicios aéreos a destinos de acceso más difícil como Bariloche y, especialmente, Puerto Iguazú. No disponemos de cifras globales respecto del incremento del turismo nacional o de la afluencia de viajeros a La Rioja o Catamarca - o a zonas ya más asentadas de turismo como los Andes mendocinos, el Noroeste o las sierras de Córdoba. Los datos que hemos podido hallar, correspondientes a los Parques Nacionales, pueden brindar sin embargo

\footnotetext{
${ }^{6}$ El crédito era otorgado por el Banco Hipotecario, pero la AGPT debía pronunciarse respecto de la zona elegida, la capacidad profesional del solicitante e inclusive el estilo arquitectónico propuesto (PIGLIA, 2012a)
} 
algunas pistas acerca del impacto de estas políticas nacionales, que se sumaron a una situación generalmente más próspera para los sectores medios, sobre todo hasta 1949. El turismo en los parques se multiplicó notablemente: en Nahuel Huapi, los 10.000 turistas de 1942 eran ya 26.000 en 1947; el crecimiento del turismo en el Parque Nacional Iguazú es más impactante aún pues se pasó de 1.544 viajeros en 1941 a 32.391 en 1947 (MDPN, 1941; 1942; SCARZANELLA, 1998) ${ }^{7}$. Como ha sostenido Eugenia Scarzanella (1998) el turismo obrero organizado contribuyó escasamente a este aumento de turistas: en 1948, por ejemplo, solo 768 obreros asistieron a los viajes colectivos de turismo social a los parques Nahuel Huapi e Iguazú. El incremento respondía más bien a la expansión del turismo de los sectores medios, que eran quienes estaban en mejores condiciones de aprovechar la democratización de los parques.

\section{Mar del Plata: La Ciudad Universal}

A finales del siglo XIX la playa y el mar irrumpieron como espacios curativos, de recreo y descanso. Nacida como un lugar de producción agropecuaria, en los años ochenta del siglo XIX, $400 \mathrm{~km}$ al sur de la ciudad de Buenos Aires, Mar del Plata se transformó en una 'estación de mar' (véase Figuras 2 y 3).

\footnotetext{
${ }^{7}$ Ciertamente, como señala Scarzanella (1998), la parte correspondiente a los parques en el conjunto del turismo nacional -en franca expansión- era muy minoritaria: en 1947 equivalía, en conjunto, a algo más del $10 \%$ de quienes se agolparon en las playas marplatenses ese mismo año. Sin embargo, si tenemos en cuenta el relativamente más dificultoso y oneroso acceso a los parques, el crecimiento de su turismo resulta significativo.
} 
Figura 2: Mar del Plata y la costa atlántica de la provincia de Buenos Aires

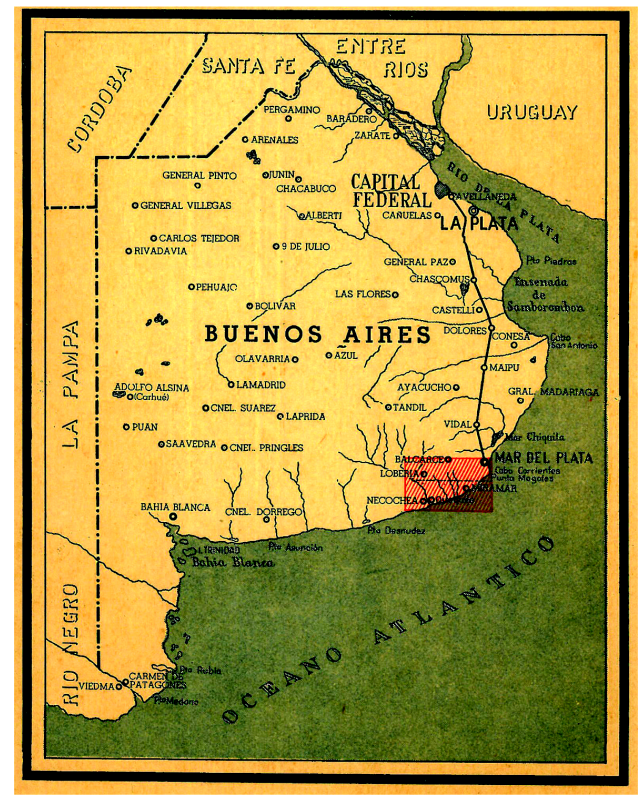

Fuente: ACA, Carta de Turismo de Mar del Plata, 1940

Figura 3: La Rambla francesa y la playa Bristol en Mar del Plata a comienzos de los años veinte.

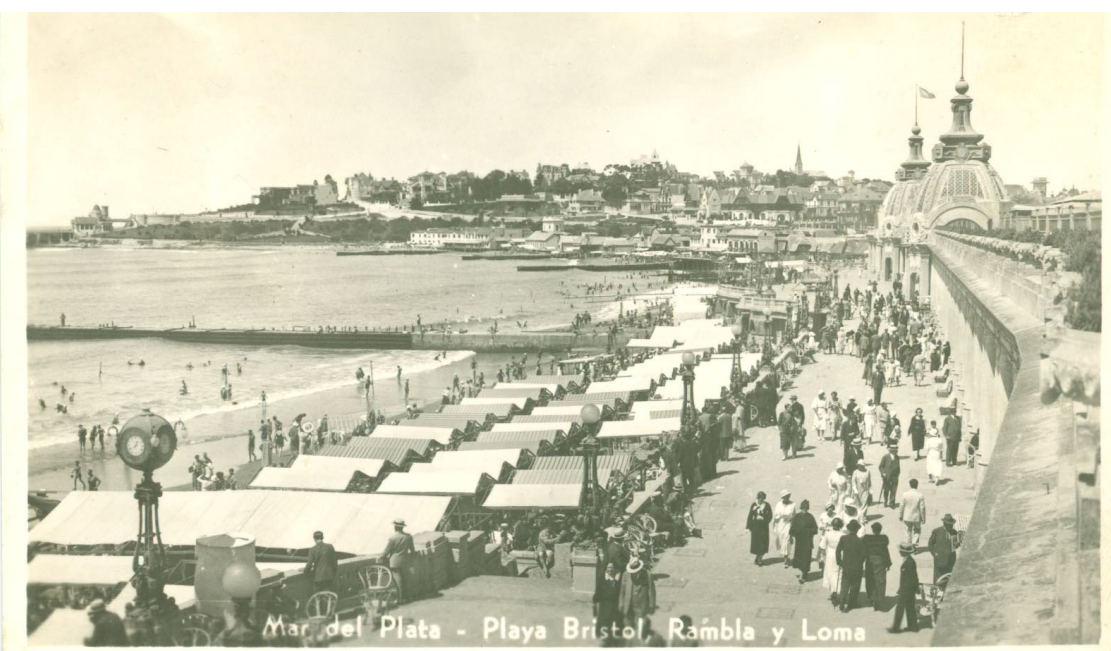

Fuente: Archivo Fondo Antiguo de la UNMdP

La llegada del Ferrocarril del Sud en 1886, la edificación de hoteles, ramblas, paseos, bulevares, tornaron aquel centro rural en el espacio propicio para el despliegue del sofisticado veraneo de las élites argentinas. Los veraneantes crecieron en gran número y construyeron elegantes mansiones; la talasoterapia fue velozmente eclipsada por la moda, el glamour y la figuración (DA ORDEN y PASTORIZA, 1990; PASTORIZA, 2011) 
Pronto, sin embargo, el reducto selecto comenzó a abrirse a nuevos grupos sociales que modificaron las viejas rutinas y hábitos $\mathrm{y}$, desde finales de los años veinte, comenzaron a llegar al balneario turistas pertenecientes a los sectores medios más acomodados. Acompañando las transformaciones económicas y sociales nacionales, entre la tercera y cuarta décadas del siglo, aquella temprana villa balnearia se abrió a nuevos visitantes que modificaron paulatinamente aquellas primeras prácticas veraniegas. De la mano de la consigna "Democratizar al balneario", tanto la sociedad civil como los poderes públicos apostaron al diseño de una ciudad balnearia marcada por nuevas prácticas sociales y culturales (PASTORIZA y PIGLIA, 2012).

El paisaje urbano fue el primero en registrar estos cambios: la tradicional Playa Bristol, luego remodelada por la gestión de Fresco, fue colonizada por los nuevos turistas (véase Figura 4), mientras las élites se desplazaban hacia el sur de la ciudad, en torno a la Playa Grande (también urbanizada por Fresco) ${ }^{8}$. La cantidad de turistas creció al ritmo de estos cambios. Mientras en la temporada 1930-31 habían arribado unos 60.000 viajeros, diez años más tarde llegaban a los 351.807 (PASTORIZA, 1999 a).

Había nacido un nuevo dibujo de la ciudad turística. Junto a ella se plasmaron sucesivas transformaciones $\mathrm{y}$, a la par del despliegue de nuevos hábitos del disfrute del ocio, se pavimentó la ruta dos que une la ciudad de Buenos Aires con Mar del Plata y emergieron una hotelería y residencias veraniegas menos lujosas y mayormente accesibles. Esta nueva cara de Mar del Plata fue premonitoria de las épocas que se avecinaban, cuando se convirtió en el retrato de la democracia social argentina (PASTORIZA, 2011).

La llegada del peronismo le daría definitivamente al balneario su perfil de masas. Los planes de la provincia de Buenos Aires (en articulación con la Confederación General

\footnotetext{
${ }^{8}$ El gobernador Fresco, que combinaba ideas modernizadoras con concepciones políticas reaccionarias, fue un pionero en ciertas políticas de turismo social (PASTORIZA, 1999b) .
} 
del Trabajo), trajeron a miles de trabajadores de vacaciones a sus costas (véase Figuras 4 y 5 y cuadros 1 y 2$)$.

Figura 4: La Playa Bristol en los años treinta. Al fondo la Rambla Francesa

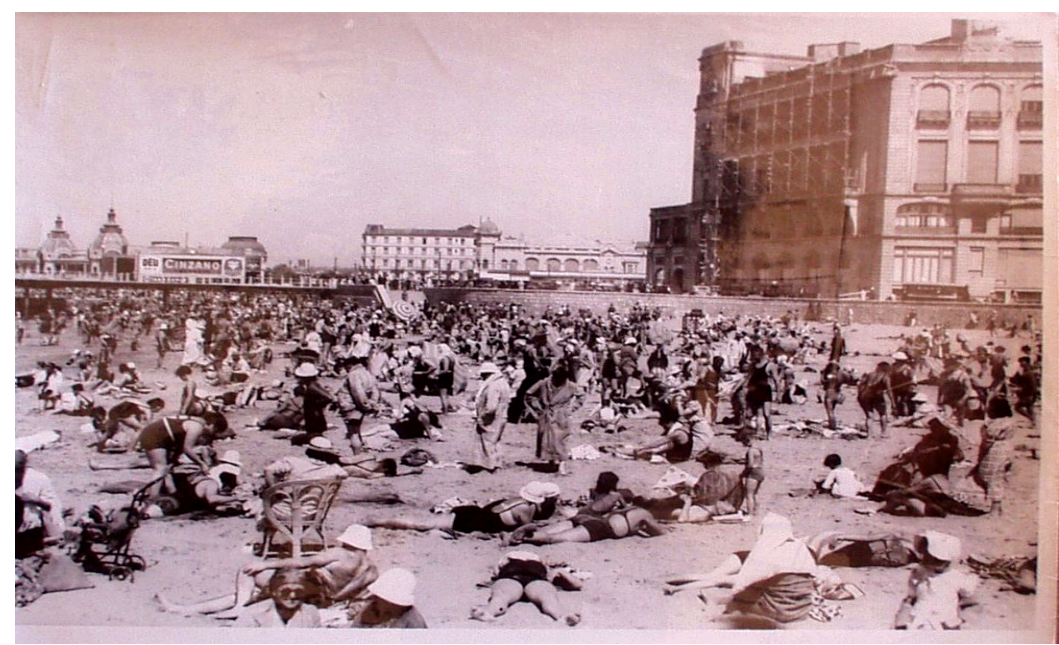

Fuente: Archivo Histórico Municipal Roberto T. Barili

Figura 5: Vista panorámica de la Playa Bristol y la nueva Rambla (inaugurada en 1938).

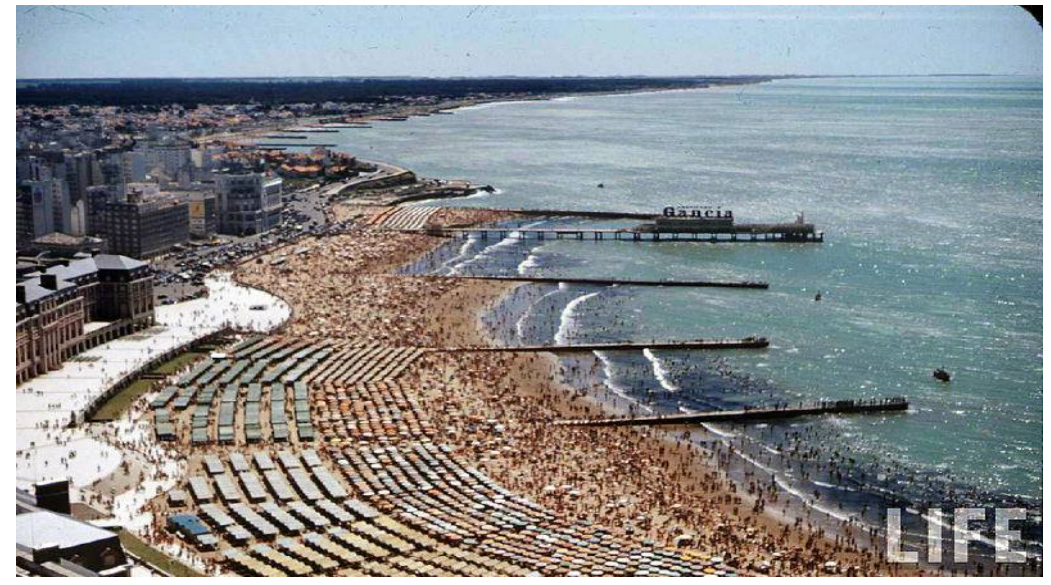

Fuente: Colección Life, fotografía Dmitri Kessel, 1958.

Desde los inicios, uno de los propósitos del Estado consistió en promover una estrecha articulación con el sector sindical, hecho que resultó particularmente favorable para el despliegue del turismo social pues los sindicatos jugaron un importante rol en la organización y prestación de ese servicio para sus afiliados. En esta atmósfera es inventada una consigna todavía recordada: "Usted se paga el viaje, el gobierno el hospedaje". Un eslogan extendido a lo largo de la Nación y que, como repetía el 
gobernador bonaerense Domingo Mercante, "Ha prendido en las fábricas, en los talleres, en las lejanas localidades rurales como la realización feliz de uno de los derechos del trabajador incorporados a la Constitución de Perón” (AHPBA, 1948, s/n).

Las vacaciones así concebidas fueron presentadas en la provincia de Buenos Aires -la primera en ensayar los planes sociales turísticos- como la conquista de un derecho cívico, fundacional, hasta ese momento inalcanzable, asociado a los premios a la producción y a la consigna “producir más y mejor”. El experimento, reconocido como una prioridad pública a la par de la vivienda obrera, estuvo auspiciado por el gobierno y canalizado por el aparato gremial de la CGT, mediante un Consejo Asesor Obrero de Turismo Social.

En una segunda etapa, su organización pasó a ser compartida con la Fundación Eva Perón (FEP). El turismo social definido como una creación de la revolución peronista, se caracterizó durante la Segunda Presidencia por el hecho de depositar en la FEP la coordinación general de las actividades recreacionales, más allá de que se las siga asociando a las organizaciones sindicales, a quienes se les facilita las condiciones para la adquisición, alquiler y uso del hospedaje.

La impronta simbólica de esta "conquista" obrera de Mar del Plata, anclada en hitos como la apertura del Casino al público general, la creación de Clubes de Turismo Social o de las Colonias Vacacionales de Chapadmalal, fue recogida con gran énfasis por el discurso peronista y, tuvo una gran perduración en la memoria pública. Sin embargo, y como han mostrado Pastoriza y Torre, todavía faltaban muchos años para que los trabajadores pudieran arribar en forma masiva a las playas. Recién en los años setenta se plasmaría esa aspiración, con la ampliación del turismo sindical (PASTORIZA, 2008a). 
En cambio, los años del peronismo posibilitaron sobre todo el avance final de las clases medias sobre Mar del Plata.

\section{Residencias Turísticas: Ocaso de la Hotelería de Lujo y Posibilidad de Acceso}

\section{a los Departamentos del Ocio}

El perfil 'de masas' de Mar del Plata implicó una nueva complejidad, con una multiplicidad de aspectos importantes para analizar, como la agudización de los desplazamientos en el espacio y los nuevos consumos. Ente ellos, los concernientes a las residencias turísticas, que tomará distintas alternativas. Coincidente con la popularización del balneario y el creciente auge de ingreso de veraneantes, las iniciativas públicas estimularon la construcción de edificios de altura, la extensión de una hotelería privada más modesta y, a su vez, la declinación de la hotelería de lujo (véase cuadros 1, 2 y 3).

Cuadro 1: Pasajeros Ingresados a Mar del Plata. Temporadas verano

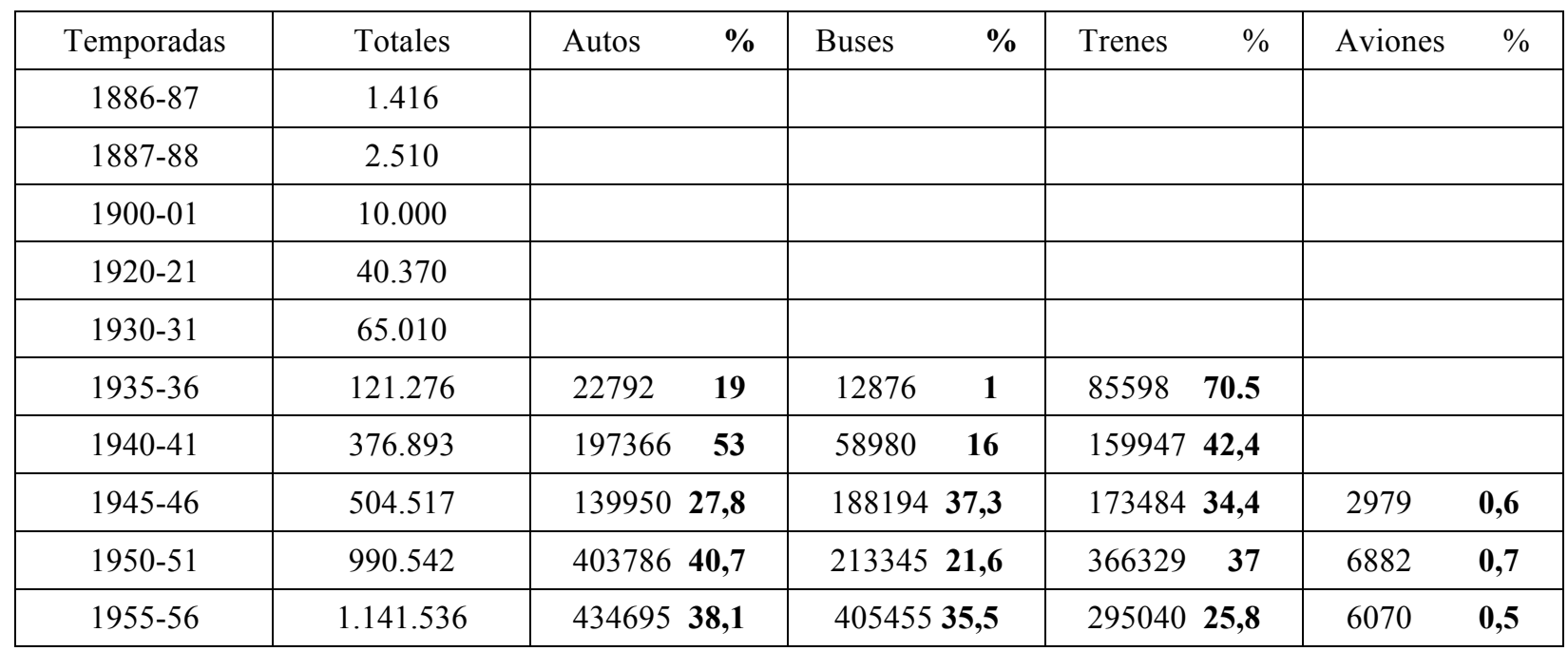

Datos: estadísticas oficiales y organizaciones privadas.

Cuadro 2. Turistas en Mar del Plata. Tasas de crecimiento (por mil)

\begin{tabular}{|c|}
\hline $1891-1916: \mathbf{7 8 . 4}$ \\
\hline $1916-1926: \mathbf{6 7 . 8}$ \\
\hline $1926-1935: \mathbf{8 1 . 8}$ \\
\hline $1935-1940: \mathbf{2 5 4 . 0}$ \\
\hline $1940-1945: \mathbf{6 0 . 1}$ \\
\hline $1945-1950: \mathbf{1 4 4 . 4}$ \\
\hline
\end{tabular}

Datos: Cuadro 1. 
El progresivo incremento de afluencia de pasajeros, que advierten los cuadros, trae aparejado una densificación de la población turística en el radio céntrico de Mar del Plata, el espacio simbólico que condensó la postal del balneario nacional. Desde sus orígenes más tempranos dicho espacio constituyó el escenario de experimentaciones urbanísticas que dejaron la huella de las diferentes etapas de su trayectoria histórica. En un viaje imaginario al pasado, hallamos una primera postal de la costa marplatense, representativa de una sociedad opulenta. La cartografía advierte una suma de construcciones urbanas en torno al ostentoso Hotel Bristol, emplazadas en la bahía comprendida entre Punta Iglesias y Punta Piedras. Allí se localizaron edificios emblemáticos (desde el Club Mar del Plata hasta el Torreón del Monje), y las ramblas (se suceden desde 1890, tres ramblas de madera y en 1913, es inaugurada la afrancesada Rambla Bristol) y también la ribera y las manzanas cercanas al mar constituyeron el ámbito predilecto donde la clase alta ubica sus ostentosos chalets estivales. Un maravilloso marco coronaba el paisaje: el jardín urbano de ocho hectáreas, el Paseo General Paz, enlazado con la Plaza Colón. Diseñado por el paisajista francés Carlos Thays, la obra siguió un trazado pintoresco con jardines, esculturas, balaustradas, dos lagos artificiales de forma irregular con sus respectivos islotes y puentecillos y con una frondosa vegetación. Estaba atravesado por senderos serpenteantes e irregulares articulados con la rambla, la plaza Colón y el futuro Boulevard.

Como ya se señaló la metamorfosis acelerada y la mutación espacial constituyeron un constituyeron un sino de la ciudad turística. Avanzando en el tiempo, aquella tranquila Estación de mar es reemplazada por una urbe populosa. En la década del treinta, el gobernador de Buenos Aires Manuel Fresco emprende una serie de iniciativas públicas transforman la fisonomía, dando lugar a una nueva postal de Mar del Plata conformada 
por el monumental complejo Rambla-Casino-Hotel Provincial enmarcado por una populosa playa Bristol. La gran transformación urbana, un proyecto pensado para un turismo de masas, acompaña la transformación social. $\mathrm{Y}$ en aquel territorio urbano cargado de simbolismo, una nueva vuelta de tuerca lo conmovió: las viejas grandes casonas caen para dar lugar a importantes edificios de altura con departamentos adquiridos por los turistas que no cesan en arribar (véase Figura 6).

Figura 6: El auge de la propiedad horizontal en Mar del Plata. Anos sesenta.

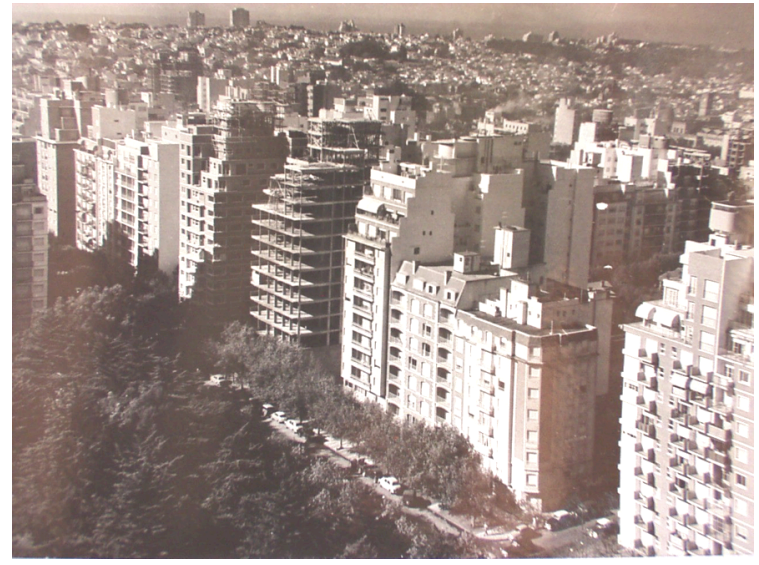

Fuente: Archivo Histórico Municipal Roberto T. Barili.

Este nuevo cuadro comprendió, además de una mayor urbanización en el radio céntrico, una densificación de la población, como también una alteración en aquella imagen de 'ciudad jardín' reemplazada por el cemento, aglomeración, contaminación y altos edificios.

Mar del Plata se convierte en un centro receptor de población: de los 33.000 habitantes en 1914 se pasa a los 72.000 en 1947, cifra que duplica en 1947, trepando a aproximadamente 220.000 en 1960 (Censos provincial y nacionales de población).

En el mencionado cuadro urbano, la hotelería acompañó estos procesos sociales, aunque no de manera rectilínea. Si bien constituyó un espejo del crecimiento turístico, lo hizo adaptándose a las alternativas de consumo adoptadas por los visitantes. 
¿Cuáles fueron los síntomas de los cambios en las rutinas del consumo? Hasta esos años, el turismo representaba un apreciado negocio para los hoteleros. Por una confluencia de razones, como el crecimiento del poder adquisitivo de las clases medias, la política de vivienda del gobierno peronista (manifestada en dos ángulos, la Ley de Alquileres y de Propiedad Horizontal), como también las modificaciones en los gustos, los turistas desdeñaron paulatinamente el uso del tradicional 'servicio' del hotel, embarcándose tras el sueño de 'adquirir un departamento'. Así tuvo lugar el nacimiento del llamado boom de la construcción para edificar edificios de departamentos, en competencia por ocupar espacio en el mercado turístico a la hotelería de tipo tradicional.

Si bien desde los albores del balneario existió un potente mercado inmobiliario, la hotelería permaneció asociada al desarrollo del balneario. Desde un hospedaje ocupado por las elites porteñas finiseculares, el surgido de emprendimientos familiares de inmigrantes desde los '20, hasta el originado por iniciativas del estado, como los diseñados especialmente para la difusión del turismo social desde fines de los años ' 40 y el hospedaje sindical. Esta clasificación se enlaza con la propia periodización de la ciudad turística (PASTORIZA y REIS, 2010).

En efecto, desde los cincuenta la expansión del turismo estuvo asociada con esta pujante actividad económica, aun cuando aparecieron competencias que amenazaban con sustraer ese lugar de privilegio. El esquema era simple: como en las épocas de oro, los nuevos veraneantes debían ser alojados en hospedajes, ahora de inferior calidad, pero con un sistema de comercialización similar. Sin embargo, el surgimiento de nuevas oportunidades permitió para aquellos de ingresos menores se comenzó a montar el sistema de turismo social (subvenciones, colonias de vacaciones, hoteles sindicales) y 
para las clases medias recién llegadas, la posibilidad de adquirir una propiedad en la ciudad junto al mar.

El flamante gobierno surgido del golpe de 1943 había sancionado un decreto estableciendo la rebaja de los alquileres, prorrogando los contratos y paralizando los juicios de desalojo y creando la Cámara de Alquileres. Cinco años después se aprobó la Ley de Propiedad Horizontal que disponía en su artículo primero: "Los distintos pisos de un edificio o los distintos departamentos de un mismo edificio o departamentos de un edificio de una misma planta, que sean independientes y tengan salida a la vía pública, directamente o por un pasaje común, podrán pertenecer a distintos propietarios" (LEY 13512, 1948). Esta normativa posibilitó direccionar los ahorros de los sectores medios hacia la compra de bienes inmuebles, permitiendo concretar la aspiración de la casa propia, también en Mar del Plata (e.g. ABOY, 2007; PILCIC, 2014).

Estas políticas públicas permitieron que en una treintena de años emergieran edificios que nutrieron con miles de departamentos destinados a los turistas, alcanzando al cincuenta por ciento del parque habitacional existente de los noventa (véase Figura 7).

Figura 7: Vista panorámica de la zona y el hotel Alfar.

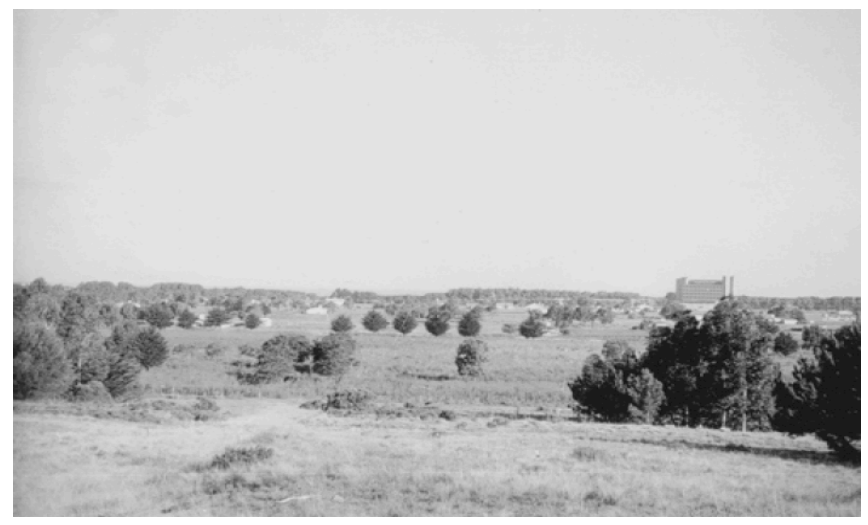

Fuente: Archivo Histórico Municipal Roberto T. Barili. 
De esta forma la franja central del balneario, en especial los chalets de la avenida Colón, fueron demolidos para dar lugar a los edificios de altura cuyo destino más seguro era el de funcionar como residencia turística (CACOPARDO, 2004; PILCIC, 2014).

La ampliación social de la emigración estacional fue acompañada por una modificación de los hábitos: los lugares de hospedaje puestos a elección de los veraneantes se diversificaron. La hotelería tradicional debió compartir su espacio con los departamentos, el hospedaje estatal y el gremial. Las primeras señales evidentes de estos cambios -y sus efectos- se palparon a fines de los '50 cuando decayó la construcción de hoteles nuevos, un alto porcentaje fue demolido mientras que otro se reconvirtió en 'propiedad horizontal'.

Cuadro 3. Evolución de la hotelería privada

\begin{tabular}{|ll|}
\hline AÑOS & HOTELES \\
\hline 1928 & 194 \\
\hline 1936 & 242 \\
\hline 1942 & 569 \\
\hline 1948 & 824 \\
\hline 1951 & 1.003 \\
\hline 1968 & 1.043 \\
\hline
\end{tabular}

Datos: estadísticas municipales y provinciales.

En paralelo tuvo lugar un rebrote de la venta de lotes. La difusión por ser 'propietario en Mar del Plata' trajo aparejado, una vez más, la valorización de la tierra y la emergencia de inversores privados en esta área económica con la consecuente multiplicación de agentes inmobiliarios por doquier. Este incremento no sólo se visualizó en el radio céntrico sino también en sus alrededores, con el loteo de los terrenos, donde las clases medias locales y también los trabajadores fueron construyendo sus viviendas (PASTORIZA, 2008a; 2008b). 


\section{Nuevos Barrios Turísticos: Más Allá del Faro Punta Mogotes}

La creciente democratización social de la ciudad, el incremento del número y variedad social de sus visitantes, tuvó un correlato espacial. No sólo se densificó la trama urbana, como vimos arriba; también se acentuó el fenómeno de extensión de su ejido . Así, la ciudad se expandió con la aparición de barrios poblados con el alto crecimiento de su población con sus 123.000 habitantes, según el Censo Nacional de 1947 y a la vez se extendieron los barrios pensados para el turismo. Uno de los epicentros fue la zona sur (véase Figura 8).

Figura 8: Plano de Mar del Plata y alrededores

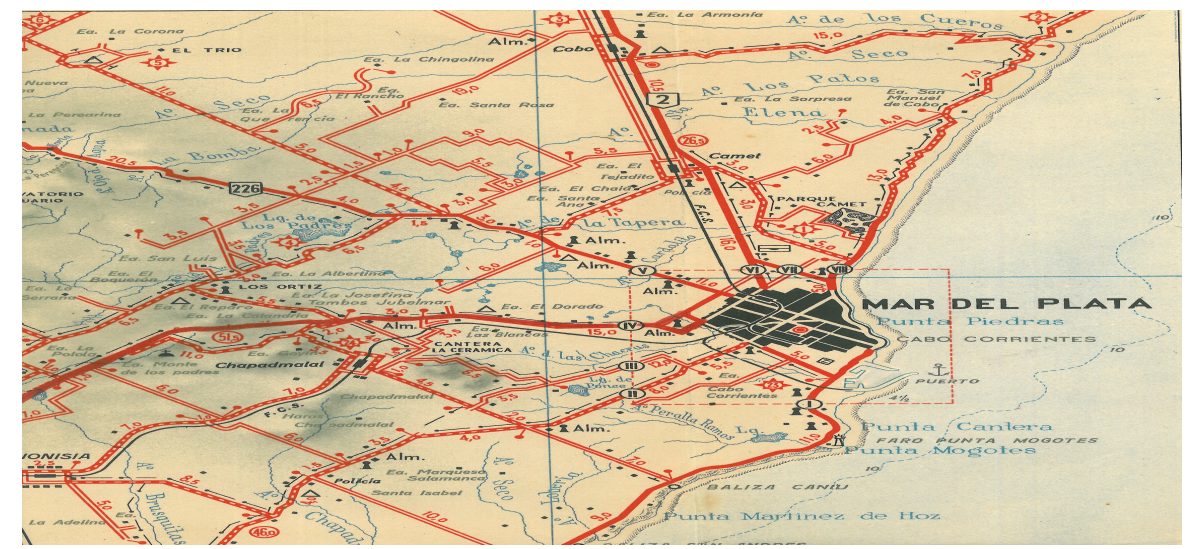

Fuente: ACA, Carta de Turismo de Mar del Plata, 1940.

Primero había sido la declaración del Pueblo de Peralta Ramos, lindante a Mar del Plata. Luego, con la circulación y urbanización posibilitada la reciente ruta 11 (la carretera hacia la vecina ciudad balnearia de Miramar), alentaron que en su entorno fueran emergiendo nuevos barrios (Mar y Sol, Los Acantilados, San Patricio, Playa Serena, San Jacinto, Alfar y Faro Norte). ${ }^{9}$ En estas iniciativas se conjugaron la participación de varios actores: asociaciones de fomento, cooperativas, sindicatos,

\footnotetext{
${ }^{9}$ El trazado del pueblo de Peralta Ramos fue realizada en los '30, durante la gestión conservadora, incorporando un área de relevancia forestal y la mayor reserva de playa y médanos del Partido de General Pueyrredón, cuya ciudad cabecera es Mar del Plata. La declaración oficial de Pueblo se produce en 1948, cuando se incorpora al ejido urbano del partido. La Ordenanza Municipal amplia a la zona urbana los siguientes barrios: Batán, el Faro (desde Punta Mogotes al sur) y Chapadmalal (Boletín Municipal nov. 1948, 44).
} 
grupos empresarios y Estado. El rol del último era justamente allanar el camino e impulsar los emprendimientos privados que provenían de la sociedad civil. Este fue el caso del origen de un proyecto de construcción de un barrio turístico para sectores medios altos, por parte de un grupo de empresarios que, con el respaldo del Estado, dieron nacimiento del denominado Barrio Alfar.

Esta iniciativa privada contó con el respaldo de los poderes públicos que aprobaron el proyecto urbano del barrio y con el financiamiento del reciente Instituto Inversor de la Provincia de Buenos Aires, que a su vez operaba con recursos del Instituto de Previsión Social bonaerense (dirigido por el Presidente del Banco Provincia, Arturo Jauretche), además de contar con amplios créditos de banco Provincia e Hipotecario (BORA, 21/07/1948).

Así, un radio cercano a 200 hectáreas de terrenos forestados cubiertos por grandes médanos atravesados por un arroyo y laguna, constituyó el escenario donde se proyectó y desarrolló un sector turístico residencial en las postrimerías de los años 40 (CASTILLO y MERTENS, 2004; PASTORIZA, 2011). En aquel espacio se hallaba en paralelo a la costa, la laguna Corrientes, la segunda en extensión en la región luego de la Laguna de los Padres, alimentada por el arroyo homónimo, cuya naciente también comprendía otros arroyos que bañan la región (Lobería, Chapadmalal, Seco y Las Brusquitas). Los trabajos previos a la construcción del barrio implicaron la eliminación de la reserva de agua dulce de aproximadamente 65 has, drenando su contenido hacia el mar por medio de un canal. Su cuenca fue cubierta por arena de la cadena de médanos que cubrían la costa, a fin de obtener un mayor número de solares para el futuro barrio, rodeados por una abundante forestación de pinos, coníferas y acacias efectuada los gobiernos provinciales 
desde los treinta en paralelo al diseño y construcción de la ruta (de AYEZA, 1995). Nacía así el Barrio Faro Punta Mogotes, luego rebautizado Barrio Alfar.

Una sociedad integrada entre otros por Narciso Machinandiarena, Rogelio Frigerio y Eduardo Enrique Aragón, adquirió una fracción de 218 hectáreas de la Estancia Cabo Corrientes a la sucesión de la familia Peralta Ramos, fundadora de Mar del Plata, para construir el nuevo barrio residencial. ${ }^{10}$ El grupo promotor contaba con varios antecedentes de inversiones y empresas en Mar del Plata relacionadas con el juego, entre ellas la concesión de las ruletas en los clubes Pueyrredón y Mar del Plata. En los años treinta, durante la gobernación de Manuel Fresco, junto con la modificación social que experimentaba el balneario, su casino se reconvirtió, transformándose en una de las salas de juego más grandes del mundo, a la que accedían los numerosos turistas que visitaban la ciudad. La Ley provincial 4588 de 1937, determinaba que el Casino provincial debería situarse a no menos de 350 kilómetros de la Capital Federal y requisitos para su explotación, como el pagar un canon, destinado a la construcción de un edificio propio. En la licitación, empañada por fuertes irregularidades, resultó ganadora a la propuesta presentada por la empresa UKA, de Miguel y Silvestre Machinandiarena y Félix Solá. Los cuantiosos montos de la inversión explican la celeridad de la emergencia del edificio del juego, que en 1939 abría sus puertas. Por añadidura, también se concedía a UKA la explotación de las salas de juego de las ciudades de Miramar y Necochea (Ley 4588 y Acta de Licitación). El gobierno nacional surgido por el Golpe Militar de 1943 declaró caducas todas las concesiones otorgadas por los gobiernos provinciales para la explotación de casinos o salas de juegos, a la vez que pasaba a considerarlos de utilidad pública y sujetos a expropiación. En 1946, Perón

\footnotetext{
${ }^{10}$ En 1864 la Estancia Cabo Corrientes tenía 7000 hectáreas, en cuyas parcelas se levantó la ciudad de Mar del Plata. El resto fue dividido entre los 12 hijos de Patricio Peralta Ramos (escritura F343R300).
} 
ratificó y profundiza dichas medidas, convirtiendo a los casinos del país en la principal actividad de ocio administrada en su totalidad por el Estado. La nacionalización peronista constituyó el comienzo a una disputa jurisdiccional entre la provincia y la nación, que se extendió hasta 1950 y llegó a la Corte Suprema de Justicia. Este litigio involucró a la Municipalidad del Partido de General Pueyrredón y a la empresa concesionaria UKA, que fue zanjado con un pago de $\$ 8.300 .000(\mathrm{~m} / \mathrm{n})$. Un magro resarcimiento en relación a lo que producían las salas de juegos, compensado por las facilidades que tanto Machinandiarena como Solá recibieron del peronismo para una variedad de intervenciones empresariales, entre ellas el barrio Alfar (PEDETTA, 2007).

Cuáles fueron los proyectos del grupo empresario? Los hermanos Miguel y Silvestre Machinadiarena además del negocio del juego, habían apostado a la próspera industria cinematográfica (Estudios San Miguel y cooperativa Artistas Argentinos Asociados) e incursionaron en el mundo editorial (Sociedad Argentina Editora).

Algunas de las personas involucradas en las empresas arriba mencionadas son las mismas que circulan en la iniciativa del barrio Alfar. La familia Machinandiarena fueron los que garantizaron el respaldo económico de estas empresas, a las que asociaron a profesionales intelectuales (universitarios, escritores, cineastas). De clase media acomodada, algunos ex militantes universitarios o de izquierda, coincidían en cierta crítica a la cultura europeísta de las élites tradicionales, en una curiosa mezcla de reivindicación nacional que miraba modelos norteamericanos. ${ }^{11}$

Ese será el horizonte en que se inscriben las imágenes del emprendimiento Alfar, un barrio turístico para sectores medios altos mediante la construcción de un hotelcasino y 80 chalets de estilo californiano ubicados en amplios lotes arbolados al sur del

\footnotetext{
11 Entre otros: Eduardo Aragón, Baltasar Jaramillo, Eduardo Calamaro, Blanca Stábile, Bernando Verbinsky, Bernardo Sofovich, Oscar Giudice.
} 
faro de Punta Mogotes. El proyecto urbano estuvo diseñado por el arquitecto modernista, el rosarino Carlos Navratil, comprendió la urbanización de un barrio de 180 manzanas irregulares, algunas triangulares que seguía la curvatura de la costa, atravesadas por tres diagonales, Norte, Central y Sur, donde sobresalía el edificio del Gran Hotel, rodeado por los chalets localizados hasta tres por manzana, sin cercos divisorios (Mensura y Subdivisión de Manzanas del Plano 45/302/48 y Lote 6 del Establecimiento Cabo Corrientes, Archivo de la Dirección Municipal de Catastro, 1948; Planimetría del Barrio Alfar, Archivo de Obras Privadas, 1949). Estos se distinguieron por su variedad de materiales (piedra Mar del Plata, revoque simil piedra, vitrea, aluminio, madera, tejas y cobre) los pórticos en arco, tanques de agua y formas abovedadas que remiten a elementos náuticos (LONGONI y POLOGNA, 2004). Construcciones modernas, diferenciadas del chalet estilo Mar del Plata, muy difundido en la época (SÁEZ, 1997). Sin lugar a dudas estas residencias apuntaban a propietarios reclutados entre las clases medias altas que pretendían un descanso alejado de la densidad urbana del radio centro y conectado con la naturaleza.

La primera sociedad constituida fue la Compañía Hotelera del Sur Argentino SRL en 1949, cuya principal inversión estuvo destinada a la construcción del hotel, financiada con créditos de los bancos Hipotecario y el Provincia. ${ }^{12}$ El edificio, ubicado en una manzana triangular en la diagonal central alcanzaba una torre principal de siete pisos (con recepción, comedores, cuatro plantas para departamentos y sala de entretenimientos en la terraza) y otro secundario para estacionamiento y servicios para el hotel. El "Hotel Alfar", estuvo pensado originariamente como Hotel-casino, lo que

\footnotetext{
${ }^{12}$ El Instituto Inversor provincial que administraba las flamantes cajas de previsión, creado en 1948 por Arturo Jauretche financió principalmente las obras, construidas por la Compañía de Construcciones Civiles de los hermanos Aragón y dos empresas subsidiarias, Indarco SRL y De Mendiguren, Betrosse y Cía (La Capital, 20-25/12/1950).
} 
sintonizaba con la tradición de los hoteles turísticos en Mar del Plata desde el legendario Bristol Hotel (1888), con los hoteles en boga en los centros vacacionales (desde Las Vegas hasta el vecino Uruguay) y con la trayectoria de sus propulsores. Dicha aspiración encontró una cerrada oposición, lo que frustró estas aspiraciones. Seguramente los poderes públicos prefirieron apostar al éxito del Hotel Provincial, que sería inaugurado poco después (1950), que había sido proyectado como un hotel-casino por el Arquitecto Alejandro Bustillo integrado el Complejo Casino-Hotel Bristol.

El fracaso en lograr la habilitación del hotel -hasta Juan Duarte, el hermano Eva Perón, la primera dama, intercedió- modificó la idea original y los empresarios decidieron convertirlo en el primer appart hotel del país, cambiando su nombre al de Torre Alfar (véase Fig. 9).

Figura 9: Detalle de las rutas costeras de la Provincia de Buenos Aires

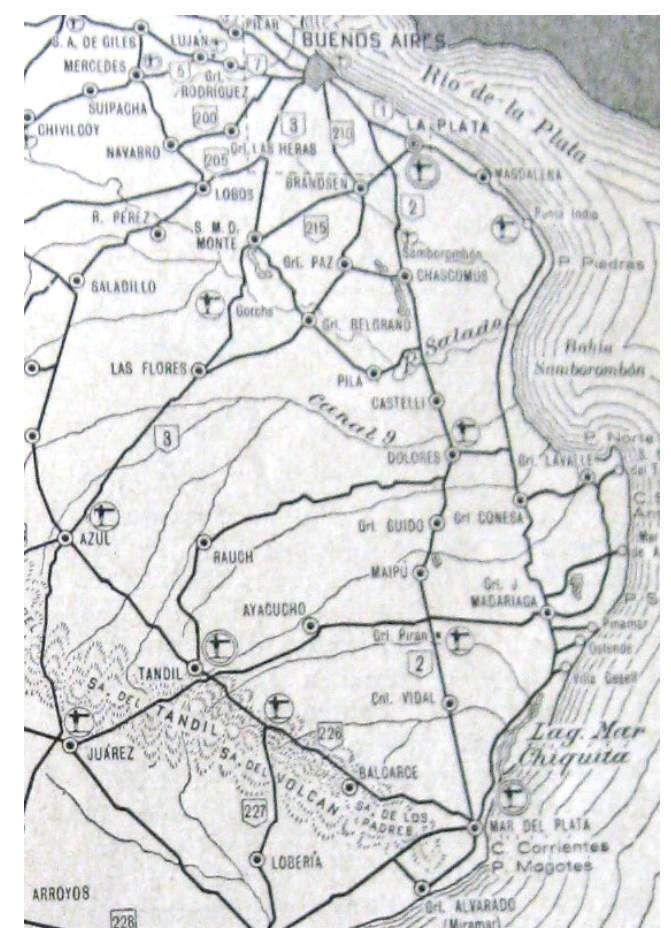

Fuente: Guia del ACA, Zona Sur, 1954 
Inaugurado el 3 de enero de 1951, sus 106 departamentos fueron puestos en venta de acuerdo a la Ley de Propiedad Horizontal (La Capital, 3-4/1/1951), con un estricto reglamento. ${ }^{13}$ Sus propietarios gozaron de modernos servicios comunes: salas de juego, varios comedores, confiterías, solárium, estacionamiento, peluquerías femeninas y masculinas. Además los departamentos, lujosamente amueblados, contaban con servicios individuales de mucamas, calefacción y radio. Un gran mural de Juan Carlos Castagnino ${ }^{14}$ presidía el salón comedor, conviviendo con una variedad de obras de prestigiosos plásticos argentinos elegidos por Blanca Stábile, la esposa de Machinandiarena (LONGONI y POLOGNA, 2004).

Más adelante, una vez puestas en funcionamiento las obras, el hotel y los chalets, se conformó una cooperativa, apelada Copefaro, que administró el nuevo barrio turístico en que se fueron asentando con el tiempo, residentes estables (Cooperativa Copefaro, 1957-67). La zona, que contaba con extensos médanos forestados y sus playas, se convirtieron con los años en una de las más codiciadas por el turismo de clase media que arribaba a Mar del Plata.

En conclusión y como decíamos al principio, entre las políticas de expansión urbana del primer Peronismo estuvieron el facilitar mediante aprobaciones, autorizaciones, ayuda económica (créditos blandos), iniciativos de actores que provenían de la sociedad civil y que apuntaron al turismo de los sectores medios. El emprendimiento del barrio Alfar, es un ejemplo paradigmático, donde se concentraron

\footnotetext{
${ }^{13}$ La Compañía Hotelera del Sud SRL, formada en 1952, administradora del hotel, elaboró estrictas normas de funcionamiento; estuvo integrada entre otros por: Narciso Machinandiarena, María Teresa M. de Bo, Delia M. de Jaramillo, Luis A. y Pedro Víctor Machinandiarena, Oscar Giúdice, Abigail P. Borthaburu, Bernando Sofovich, Rogelio Frigerio, Félix Solá y los marplatenses Ernesto y Juan José Ameztoy, Francisco Martín y José Guerra. Estas personas también adquirieron residencias Fuente: Edificio ALFAR-Testimonios-Reglamento de Co-propiedad y Administración- Mar del Plata, 1954.

${ }^{14}$ El mural de Juan Carlos Castagnino, ubicado en el primer piso, se denomina La historia y su autor nacido en Mar del Plata y uno de los plásticos más prestigiosos de la Argentina- lo concibió con forma de ele $(\mathrm{L})$, con una dimensión extraordinaria.
} 
aspiraciones, vínculos, y también tensiones, que marcaron esa idea de constituir una 'ciudad turística de todos'.

\section{La Política Turística en la Provincia de Buenos Aires: Caminos y Balnearios}

Como vimos, la política turística del peronismo no sólo se articuló a nivel del gobierno nacional y los planes de turismo social de la provincia de Buenos Aires, habían sido pioneros y marcado un camino que luego seguiría el gobierno nacional peronista. Sin embargo, el turismo social no agotaba la política turística peronista de la primera provincia argentina

Según se expresaba a propósito de la creación de la Dirección Provincial de Turismo en 1947, para Mercante, la política turística de la provincia de Buenos Aires se basaba en un triple objetivo: "turismo cultural, turismo social e industria turística". Así, además de democratizar el acceso a las vacaciones y la recreación y de complementar la educación popular con el turismo socio-cultural, Mercante sostenía que el Estado debía a solucionar los "problemas fundamentales" del turismo para "[...] establecer sobre bases sólidas la prosperidad económica de la industria turística", fuente de riquezas y de trabajo para la Provincia (MERCANTE, 1947, p. 36). A la vez, la mirada sobre esta industria tuvó un cariz territorial: la provincia se dividió en cuatro "zonas de turismo" (Lagunas, "Mar y Sierras", Delta y norte y "Cruz del Sur") en las que se organizaron en 1947 y 1948 conferencias regionales de turismo.

La política de fomento de la industria turística se orientó en dos direcciones. Por un lado, se buscaba abaratar la hotelería, regulándola a través de un registro de hosterías y afines que permitiera la homologación de su calidad y el control de los precios y estimulando la construcción de hoteles económicos, hosterías y campamentos en diversas 
localidades de la provincia (Miramar, Carhué, Chascomús, etc.). Por el otro, se procuró facilitar el acceso a los lugares turísticos, incluyendo una serie de obras viales en el Plan Trienal de obras Públicas de 1947.

El Plan Trienal de 1947, era un plan maestro en el que caminos, obras de hidráulica y obras de arquitectura se articulaban y que centralizaba el control de las obras públicas en manos del gobernador y del ministro de Obras Públicas. ${ }^{15}$ En materia de caminos turísticos, la atención se concentró de forma especial en dos de estas zonas. En primer término, en “Mar y Sierras”, la región que comprendía a Mar del Plata, a otra serie de balnearios (desde Miramar al sur, hasta San Clemente al norte -Véase Figura 9) y a las localidades serranas de Balcarve, Tandil y Azul en el corazón agropecuario de la Provincia. En esa zona, se atendió en particular a los balnearios de la costa atlántica norte de la provincia (entre San Clemente y Villa Gesell -véase Figura 9). En segundo lugar, se emprendieron obras viales en la zona norte, cerca de la capital de la Provincia, la ciudad de La Plata, mejorando el acceso a Punta Lara (Véase Figura 2).

La política de construcción y pavimentación de caminos en "Mar y Sierras" revela una voluntad de intensificar no solo la conexión de la zona con la el área metropolitana ${ }^{16}$, el gran mercado emisor de turistas, sino también el deseo de aumentar las interconexiones dentro de esa zona turística. Por un lado, esto podría permitir acrecer el caudal de visitantes a los balnearios, sumando a los residentes de la serranía una zona enormemente próspera. Sin embargo, consideramos que la finalidad principal era otra: distribuir de manera planificada los flujos de turistas veraniegos, que se aglomeraban en Mar del Plata, dirigiéndolos, como si de riego se tratara, hacia áreas con

\footnotetext{
${ }^{15}$ Otras normas acentuaron la centralización, como la ley ampliatoria del Plan Trienal, en 1948, la ley regulatoria del Consejo de Obras Públicas o la nueva ley general de vialidad que recortaba la autarquía de la Dirección Provincial de Vialidad (Ley 5238/1947).

${ }^{16}$ En la ciudad de Buenos Aires y su cinturón conurbano vivía en 1947 casi el 30\% de la población del país (LOBATO y SURIANO, 2000, p. 565).
} 
potencial para desarrollarse turísticamente (como la costa atlántica norte); o hacerlos circular entre localidades turísticas para derramar prosperidad sobre regiones más amplias (como en el circuito entre Mar del Plata, Miramar y Tandil -véase Figura 9). Esto prometía además incrementar el número de viajeros, al aumentar la diversidad de destinos posiblos en un contexto de movilidad ascendente y creciente diversificación de los mercados consumidores de turismo (que, insistimos, seguían siendo fundamentalmente de sectores medios).

La creación de esos nuevos balnearios se remontaba a mediados de los años treinta, cuando algunos terratenientes encontraron en la fundación y el loteo de villas turísticas, la posibilidad de valorizar fondos de estancias escasamente productivos y poco accesibles, a los que podía llegarse en un comienzo solamente por mar, circulando en automóvil o a caballo por la playa durante la bajamar, o completando el largo viaje en tren hasta la estación de Juancho con un trayecto hasta la costa en sulky (BERTONCELLO, 1993). A la fundación de San Clemente del Tuyú (1934) y Mar de Ajó (1936) le seguirían pocos años después Santa Teresita, Mar de Ajó Norte, San Bernardo y, más al sur, Villa Gesell, Cariló y Pinamar. Estos nuevos emprendimientos se apoyaban de forma fundamental en los avances de la construcción del Camino Costanero de La Plata a Mar del Plata, una obra que la Provincia había emprendido en 1933. El camino, que en buena parte de su traza era de tierra, se inauguró en 1936 y se complementó con otro, entre Dolores y General Conesa, que lo vinculaba con el camino directo y pavimentado Buenos Aires-Mar del Plata (véase Figuras 2 y 9). Al sur de la Bahía de Samborombón, el Costanero corría sin embargo a unos 70 km de la costa, por lo que el acceso a los balnearios era a través de caminos "naturales", sometidos a los avances de las dunas. 
Entre 1948 y 1950 el Plan Trienal de 1947 avanzó en la realización de obras para mejorar el camino entre Dolores y el Costanero y también de caminos permanentes que lo vincularan con la costa, a la altura de los balnearios de Mar de Ajó y San Clemente. Poco después se inició la construcción de un tercer camino que en su tramo final conectaba la costa a la altura de Pinamar, Villa Gesell y Cariló, con las prósperas localidades serranas del centro de la Provincia (TANDIL y AZUL, véase Figuras 2 y 9).

Casi al mismo tiempo se emprendieron las obras en Punta Lara. El balneario, había sido un lugar atractivo para la élite en sus comienzos, pero ya desde los años treinta había perdido su favor y adquirido un carácter cada vez más plebeyo ${ }^{17}$. Durante el gobierno del conservador Manuel Fresco (1936-1940), se había iniciado la construcción de un parkway que conectaba al popular balneario con otra playa muy concurrida, Quilmes. El camino se incluyó en el Plan Trienal y se lo extendió; las obras se llevaron a cabo entre 1948 y 1950. Otro camino al balneario, que lo unía con la ciudad de La Plata y que había sido ya previsto pero no ejecutado en el plan de 1944, se construyó entre diciembre de 1949 y 1951 (véase Figuras 2 y 9). ${ }^{18}$

La inversión en los caminos a Punta Lara, formaba parte de la política de turismo social, que incluía mejorar o crear parques, playas y balnearios populares cercanos a los grandes centros poblados “destinadas a proporcionar al trabajador lugares apropiados y económicos de distracción y descanso" (EL ARGENTINO, 6-2-1947, p. 9) ${ }^{19}$. Las obras viales que mejoraban las conexiones del balneario, potenciaban los

\footnotetext{
${ }^{17}$ Así, por ejemplo, el Automóvil Club Argentino, que había alquilado desde 1928 un predio donde había construido un recreo, lo abandonó en 1932 "en razón de las características del público que concurre habitualmente a esa playa". (Automovilismo julio-agosto de 1932, 13).

${ }^{18} \mathrm{La}$ mayor parte de las obras son financiadas en parte o de forma completa, con fondos de coparticipación federal.

${ }^{19}$ En ese marco la provincia expropió, en 1949, el Swift Golf Club de Gonnet -luego Ciudad de los Niños- y una parte de las tierras de la Familia Pereyra Iraola, para destinarlas a asegurar la recreación de los sectores populares de La Plata, de Buenos Aires y de los muy poblados distritos que rodeaban a la Capital (MERCANTE, 1949, p.19).
} 
servicios de ómnibus de media distancia en los que podían trasladarse los obreros y sus familias, pero apuntaba también a franjas de los sectores populares con acceso a automotores: quienes poseían o trabajaban con taxis y camiones, los pequeños comerciantes o los empleados de situación algo más desahogada que disponían de un automóvil o podían alquilarlo para una excursión dominical.

Las obras viales en la costa atlántica norte, en cambio, parecen responder más bien a una voluntad estatal de fomento de la industria turística, intensificando la integración territorial y ampliando la oferta de turismo accesible a los sectores medios. Apuntaba como dijimos a aprovechar, no sólo la expansión el número de viajeros, sino también la creciente segmentación del mercado, distribuyendo el caudal de turistas entre diferentes destinos, consagrados y nuevos. Esto se vinculaba con la emergencia de tendencias novedosas en el desarrollo del turismo, que respondían tanto a la dinámica de los procesos de imitación y distinción sociales, como a otras transformaciones culturales que se reflejaban en los cambios en patrones de gusto y de consumo. Así, mientras continuaba el crecimiento y la ampliación social de principal balneario de la costa atlántica argentina, Mar del Plata, ya desde fines de los años treinta, y como respuesta a la agitación, la masividad y la hiper-urbanización del veraneo marplatense, comenzaron a desarrollarse nuevas modalidades turísticas. Centradas en el deseo de un mayor contacto con la naturaleza y en la búsqueda de tranquilidad, asociadas al descanso y la salud, estas modalidades, que involucraban sobre todo a los sectores medios, impulsaron en los años cuarenta el crecimiento de los balnearios de la costa atlántica norte (BRUNO, 2002; PASTORIZA, 2011).

Inicialmente Mar de Ajó y San Clemente habían atraído tanto a algunos compradores de solares que comenzaron a construir sus residencias, como a un turismo 
de sectores medios más modestos, para los que Mar del Plata resultaba demasiado onerosa, que se alojaban en los hoteles y pensiones o en los campings del Automóvil Club Argentino (ACA). Para comienzos de los años cuarenta, una serie de emprendimientos en esas localidades y la creación de nuevos balnearios como los de San Bernardo, Santa Teresita, Villa Gesell o Pinamar, procuraron atraer a sectores medios que buscaban en estos nuevos destinos la tranquilidad, el ambiente familiar y el descanso, pero también una fuente de distinción. Se trataba de sectores que no tenían posibilidades de poseer a una residencia de verano en Mar del Plata (sobre todo antes del boom de los departamentos de veraneo en Mar del Plata), pero podían, en cambio, comprar, en cuotas, un terreno en San Clemente o, a partir de 1947, en la naciente Villa Gesell. Esto se veía favorecido por los créditos para viviendas de veraneo, que, como dijimos, estaban incluidos en la ley de crédito hotelero de 1947 (MAGPT, 1947, p. 13).

Estos cambios en las pautas de consumo turístico, que eran ya evidentes a principios de los años cuarenta, abrían nuevas oportunidades empresariales: así, en 1943 el ACA proyectó transformar las 20 hectáreas de su "camping de playa" en San Clemente en un moderno y confortable balneario, rodeado de un barrio parque de residencias veraniegas - con cuyo loteo se esperaba financiar las obras. Poco antes, en 1941, Carlos Gesell había abandonado definitivamente sus proyectos de explotación forestal e iniciado el camino para transformar sus tierras en la costa del partido de General Madariaga en un balneario (PASTORIZA, 2011), mientras Héctor Guerrero daba por terminada su empresa de producción de manzanas en el mismo partido para encarar un balneario en la actual Cariló (HARISPURU, 2012). Relativamente alejados de las estaciones de ferrocarri1 ${ }^{20}$ el acceso a estos balnearios era prioritariamente en automóvil (o en buses), por lo que la construcción de buenos caminos, aparecía como

\footnotetext{
${ }^{20}$ La estación de tren estaba a unos 20 kilómetros de Villa Gesell, pero a más de 60 de Mar de Ajó
} 
un requisito fundamental para su desarrollo. ${ }^{21}$ Se trataba todavía, pese a las expectativas de los empresarios, de un crecimiento incipiente, que sin embargo marcaba una tendencia hacia el futuro, suficiente para convencer a los gobernantes de invertir cuantiosos recursos públicos en dotar de caminos a esa región. ${ }^{22}$ La afluencia de turistas se aceleraría recién a fines de los años cincuenta y en los años sesenta y setenta, cuando el departamento o la casita en la costa se convertirán en un atributo clave del ascenso social de los sectores medios. ${ }^{23}$

\section{Conclusiones}

Desde los años treinta, en un proceso acentuado por los efectos de la crisis económica, las elites dirigentes y las burocracias estatales actualizaron el diagnóstico de los males argentinos en clave territorial. La construcción de una red de caminos, una necesidad para la producción agroexportadora abrumada por los costos del flete ferroviario, pareció prometer también una solución en este sentido, acercando lo lejano en un país marcado por la extensión (BALLENT y GORELIK, 2002); de la política turística se esperaba que estimulara además el sentimiento patriótico y la integración simbólica del territorio (PIGLIA, 2012a).

Las políticas turísticas y de vialidad turística que hemos analizado aquí tuvieron efectos territoriales: estimularon la turistificación y urbanización de espacios rurales sobre la base de segundas residencias (desde los balnearios de la costa al norte de Mar

\footnotetext{
${ }^{21}$ El otro requisito era la fijación de dunas, que había sido atendida por la provincia durante la gobernación de Fresco (sobre todo en los balnearios del actual partido de la costa) o por los propios empresarios de los balnearios, como en Villa Gesell y Pinamar (PIGLIA, 2012b; BRUNO, 2002).

${ }^{22}$ En la génesis de estas políticas estaba, seguramente, aunque resulte difícil reconstruirla con certeza, la eficaz presión de quienes tenían intereses en la zona.

${ }^{23}$ La afluencia de sectores medios a estos nuevos balnearios se vinculó también con otros fenómenos, iniciados por el peronismo, como el auge del turismo popular y masivo en Mar del Plata (que se consolida con el turismo sindical en los años sesenta y setenta), que impulsarán a buena parte de los sectores más acomodados, hacia destinos socialmente más homogéneos, beneficiando tanto a algunos de los balnearios al norte de Mar del Plata como a la costa uruguaya (PASTORIZA, 2011).
} 
del Plata, hasta el propio Barrio Alfar), alteraron, densificándola, la trama urbana del balneario principal en el que se multiplicaron los edificios en altura, crearon una infraestructura hotelera de escala nacional capaz acercar a la realidad el imperativo patriótico de conocer el país. Formaron parte, además, de intervenciones más amplias a escala nacional y provincial (la pavimentación de caminos nacionales y provinciales, por ejemplo), que intensificaron la integración territorial desde el punto de vista material, y e hicieron posible que crecientes sectores sociales se apropiaran de ese territorio a través de las prácticas turísticas.

Como vimos, en términos generales las políticas peronistas, nacionales y provinciales, pusieron el turismo al alcance de crecientes sectores sociales, convirtiendo a las vacaciones en un derecho. Los planes de turismo social dejaron una impronta indeleble en el imaginario y parecían hacer realidad esta "conquista" de los trabajadores. Aunque el discurso público del peronismo hiciera un énfasis casi exclusivo en el acceso de los trabajadores a las vacaciones, estos planes también estaban dirigidos a fracciones modestas de los sectores medios (PASTORIZA, 2011).

El turismo social cuenta sin embargo solo una parte de la historia. Como hemos mostrado a lo largo del trabajo, una parte no menor -aunque menos estridentemente promocionada- de la política peronista se orientaba a estimular al turismo como fuente de riqueza, como "industria". Para ello, era menester atraer al "turismo pudiente" -como lo designaba un funcionario del Ministerio de Asuntos Técnicos en 1947 (PLAN DE TURISMO 1947)-, es decir al crecientemente diversificado mercado de los sectores medios, ávidos de viajar y cuyas franjas más modestas recién estaban consiguiendo acceder al disfrute de las vacaciones. Es necesario resaltar, frente al énfasis discursivo del peronismo en las vacaciones obreras (o la imagen de la "Mar del Plata Obrera"), que 
en los años cuarenta y cincuenta, las vacaciones eran una aspiración, centralmente, de los sectores medios en ascenso; en trabajos previos hemos dado cuenta también de las resistencias que el hábito de las vacaciones encontró inicialmente para su difusión entre los sectores obreros (PASTORIZA, 2011).

Como vimos, una serie amplia de políticas (viales, propiamente turísticas, crediticias) nacionales y provinciales apuntaron a este objetivo, estimulando el desarrollo de una hotelería más amplia y económica, el crecimiento o la creación de nuevas localidades turísticas o de nuevos espacios dentro de las tradicionales (como en el caso del Barrio Alfar), la diferenciación del mercado turístico y la adquisición de segundas residencias. La trayectoria de Mar del Plata, el emblemático balneario argentino, da cuenta de este proceso por el que los sectores medios completaron su "conquista" de las vacaciones. Por detrás se encuentran por supuesto una serie de transformaciones culturales, reflejadas en la consolidación de las imágenes y prácticas en torno al veraneo en la playa (desde la identificación del departamento en torre con la imagen de una "vida moderna" hasta la exaltación de la naturaleza y la vida natural). A la vez, el auge de los departamentos en la costa (o de los terrenos en los nuevos balnearios) es impensable por fuera de una trama de políticas peronistas, que redistribuyeron renta en favor de sectores obreros y medios, habilitaron la propiedad horizontal, financiaron a empresarios y compradores, pavimentaron rutas y abarataron el transporte.

Estas políticas tuvieron ciertamente una finalidad de fomento del desarrollo económico, de aliento de la "industria turística" a partir de la creación de condiciones favorables para las inversiones privadas. A la vez aumentaron las oportunidades de esparcimiento de los sectores medios y estimularon en ellos la práctica de las 
vacaciones. Este era un objetivo deliberado no solo porque se trataba, como ya hemos dicho, de sectores con algún poder adquisitivo, dispuestos -y deseosos- de gastar ese dinero extra en consumo turístico, y por lo tanto eran la clientela natural para esta industria. Lo era también por motivos sociales: consideramos que algunas de estas políticas evidencian que los sectores medios formaron parte del horizonte de inclusión social del peronismo, cristalizado en el slogan de la "Mar del Plata universal". 24

En el contexto de una sociedad móvil que posibilitaba la llegada al consumo de nuevos bienes, servicios y prácticas para sectores cada vez más amplios, el turismo popular durante el peronismo, no equivalía a turismo obrero y mucho menos a turismo social, sino que se extendía para incluir también a las fracciones más modestas de los sectores medios: los empleados más acomodados, los pequeños comerciantes y los pequeños propietarios. En ese sentido, consideramos, la democratización social implicó un complejo proceso que el peronismo tuvo la audacia de encarar: entrelazar lo popular con la cultura de masas, cuyas porosas fronteras resultan difíciles demarcar, y también incorporar en esa cultura popular prácticas y registros representativos de las clases medias. Parafraseando a Stuart Hall (1984, pp. 93-109), esto implicó un proceso de tensión continua, con relaciones cambiantes y desiguales, con elementos estables e inestables, y antagonismos con la cultura dominante.

\section{REFERENCIAS}

ABOY, Rosa. Vivir con otros. Una historia de los edificios de departamentos en Buenos Aires, 1920-1960. Tesis de Doctorado en Historia. Universidad de San Andrés, Buenos Aires, 2007.

ACTAS, Informes y Balances de la Cooperativa Copefaro (Cooperativa Copefaro), en su primera época, 1957-67. Mar del Plata, Archivo Museo Magrassi.

\footnotetext{
${ }^{24}$ Así la presentaba, por ejemplo, el periódico mercantista El Argentino (El Argentino, 10-2-47).
} 
ANEXO Plan de turismo, Fondo asuntos técnicos, expediente 395, AGN.

AUTOMOVILISMO, Revista del Automóvil Club Argentino. 1945-1955.

BALLENT, Anahí y GORELIK, Adrián. "País urbano o país rural: la modernización territorial y su crisis". En: Nueva Historia Argentina, tomo VII, Los años treinta, dir . Alejandro Cataruzza, 143-200. Buenos Aires: Sudamericana, 2002.

BARANOWSKI, Shelley. Strength Through Joy: Consumerism and Mass Tourism in the Third Reich. Nueva York y Cambridge: Cambridge University Press, 2007.

BERTONCELLO, Rodolfo. "Configuración socio-espacial de los balnearios del Partido de la Costa (Provincia de Buenos Aires)". En Territorio, v. 5, n. 5, Instituto de Geografía, FFyL, UBA, 1993.

BOLETÍN Municipal. Municipalidad de Gral. Pueyrredón. 1948-1955.

BOLETÍn Oficial de la República Argentina (BORA).

BRUNO, Perla. "La humanización del paisaje". En Construcción de paisajes. Transformaciones territoriales y planificación en la región marplatense. 1930-1965, eds. Perla Bruno y Carlos Mazza, pp. 57-88. Mar del Plata: UNMdP- FAUD, 2002.

CACOPARDO, Fernando. Radiografía de una ciudad mutante. Mar del Plata: EUDEM, 2004.

CASTILlO, Ricardo y MERTENS, Carlos. Historias del Sur. Programa la Cultura y los barrios. Mar del Plata: Suárez, 2004.

CORBIN, Alain. El territorio del vacío. Occidente y la invención de la playa (17501840). Barcelona: Mondadori (Grijalvo), 1993.

DA CUNHA, Nelly y CAMPODÓNICO, Rossana. 2012. Uruguay. Hacia la noción de país turístico, 1930-1955. En Anuario IHES, 37: 331-367.

DA ORDEN, María L. y PASTORIZA, Elisa. "La formación de una ciudad moderna: grupos sociales y ámbitos culturales". En Mar del Plata, una historia urbana, AA.VV, pp. 165-207. Buenos Aires: Fundación Boston, 1990.

DE AYESA, Félix. "El mito de la Laguna Corrientes y el Marquesado". En Serie Comunicaciones, v. 2, n. 22, p. 4-9, Mar del Plata: Archivo Histórico Municipal, 1995.

ESCRITURA F343R30, Narciso Machinadiarena adquiere a Sra. Julia Alcira Peralta Ramos de Hernández y otros el lote 6-cuartel IV, 30/12/1947. Escribanía Abel M. Jaramillo, 1947.

GERCHUNOFF, Pablo y LLACH, Lucas. El ciclo de la ilusión y el desencanto. Un siglo de políticas económicas argentinas. Buenos Aires: Editorial Ariel, 1998. 
GERMANI, Gino. Política y sociedad en una época en transición. Buenos Aires: Paidós, 1965.

HALL, Stuart. "Notas sobre la desconstrucción de 'lo popular'”. En Historia popular y teoría socialista, dir. Raphael Samuel, p.93-109. Barcelona: Crítica, 1984.

HARISPURU, Adela. "Cariló, o cuando el médano fue verde". En Revista de Historia Bonarense. Morón: Archivo Histórico de Morón, n. 40, p. 54-63, 2012.

LOBATO, Mirta y SURIANO, Juan. Atlas histórico, Nueva Historia Aergentina. Buenos Aires: Sudamericana, 2000.

LONGONI, René y POLOGNA, Elba. “Otra mirada a la costa atlántica”. En: Summa, n. 68, p. 88-93, 2004.

MEMORIA de la Dirección de Parques Nacionales (MDPN) 1940-1943.

MEMORIAS de la Administración General de Parques y Turismo (MAGPT) 19471950 .

"MENSURA y Subdivisión de Manzanas del Plano 45/302/48 y Lote 6 del Establecimiento Cabo Corrientes". Propiedad Narciso Machinandiarena, del Agrimensor E. Ameztoy, Cuartel IV-Archivo de la Dirección Municipal de Catastro. MGP, 1948.

MERCANTE, D. 1947 "Mensaje de apertura de las sesiones ordinarias y Memorias de la labor de gobierno en 1947'. En Mensajes de los gobernadores de la Provincia de Buenos Aires, edición digital. La Plata: Museo Histórico de la Provincia de Buenos Aires, 2002.

PASTORIZA, Elisa. "Sociedad y política en la conformación de un balneario de masas. Mar del Plata en los años treinta". Tesis Maestría en Historia, UNMDP, Mar del Plata, 1999a.

" "Restricción política y reforma social en la provincia de Buenos Aires: La gobernación de Manuel Fresco (1936-1940)". En CONGRESO NACIONAL Y REGIONAL DE HISTORIA ARGENTINA, 10, Academia Nacional de la Historia, Santa Rosa, La Pampa, 1999b.

. (Ed.). Las puertas al mar. Buenos Aires: Biblos, 2003.

. "Estado, gremios y hoteles. Mar del Plata y el peronismo". En: Estudios Sociales, Revista Universidad Nacional del Litoral, v. 34, n.1, p.121-147 , 2008a.

2008b. "El turismo social en la Argentina durante el primer peronismo. Mar del Plata, la conquista de las vacaciones y los nuevos rituales obreros, 1943-1955". En Nuevo Mundo Mundos Nuevos, Debates, 2008a. Disponível em: http://nuevomundo.revues.org//index36472.html. Acesso em: 062016.

. La Conquista de las vacaciones. Buenos Aires: Edhasa, 2011. 
; y PEDETTA, Marcelo. "'Lo que el pueblo necesita'. Turismo social y Peronismo. Argentina, 1945-1955.". En: Études Caribéennes [en línea], 13/14, 2010. Disponível em: http://etudescaribeennes.revues.org/3767. Acesso em: 062016.

PASTORIZA, Elisa y PIGLIA, Melina. "Asociaciones civiles, empresas y Estado en los orígenes del turismo nacional”. En: Anuario del IEHS, n. 27, p. 393-416, 2012.

y Reis, Fernanda. "Recuerdos de la vida en los hoteles de la costa". En: PASTORIZA, E. (Ed.). Un Mar de memoria. Historia e imágenes de Mar del Plata. Buenos Aires: EDHASA, 2010, p. 84-105..

PEDETTA, Marcelo. "Los Casinos en la Costa Atlántica entre la Nación y la provincia. Disputas por el botín, 1944-1950". En El gobierno de Domingo A. Mercante en Buenos Aires (1946 - 1952). Tomo III, dir. Claudio Panella. La Plata: Archivo Histórico de la Provincia de Buenos Aires, 2007. p. 107-128.

PERIÓDICO El Argentino, La Plata. 1947-1950

PIGLIA, Melina. "The Awakening of Tourism: The Origins of Tourism Policy in Argentina, 1930-1943”. En Journal of Tourism History, v. 3, n. 1, p. 57-74, 2011.

2012 a. "En torno a los Parques Nacionales: primeras experiencias de una política turística nacional centralizada en la Argentina (1934-1950)". En PASOS, Revista de Turismo y Patrimonio. Universidad de la Laguna v. 10, n. 1, p. 61-73.

"Turismo y obra pública. José María Bustillo y la política turística del gobierno de Fresco.". En Revista de Historia Bonarense, Archivo Histórico de Morón, n. 40, p. 14-23, 2012 b.

Autos, rutas y turismo. El Automóvil Club Argentino y el Estado. Buenos Aires: Siglo XXI, 2014.

PILCIC, Talía. "Una nueva imagen de la ciudad. La explosión inmobiliaria y la expansión social, entre 1948 y 1979”. Tesis de Licenciatura en Historia, UNMDP, Mar del Plata, 2014.

PLANIMETRÍA del Barrio Alfar, Archivo de Obras Privadas, MGP, 1949.

"PRIMER Congreso Obrero de Turismo Social", AHPBA (Archivo Histórico de la provincia de Buenos Aires), Gob. Bs. As., La Plata, 1948.

SAÉZ, Javier. 1997. “La Máquina promiscua. El estilo Mar del Plata y la formación del espacio doméstico entre 1935 y 1950". En Apuestas entre dos horizontes. Mar del Plata, ciudad e historia, ed. Fernando Cacopardo. Buenos.Aires: Alianza, 1997.

SCARZANELLA, Eugenia. "El ocio peronista: vacaciones y "turismo popular" en Argentina (1943-1955)”. En Entrepasados, n. 14, p. 65-84, 1998.

II PLAN QUINQUENAL. Buenos Aires: Presidencia de la Nación, 1953. 
TORRE, Juan C. Y PASTORIZA, Elisa. "La democratización del bienestar". En Los años peronistas. Colección Nueva Historia Argentina, Dir. Juan C. Torre. Buenos Aires: Sudamericana, 2002. p. 257-312.

WALTON, John. The English Seaside Resort. A Social History, 1750-1914. New York: Leicester University Press-St.Martin's Press, 1983.

\section{Endereço das Autoras:}

Melina Piglia

CEHIS-INHUS, CONICET

Facultad de Humanidades, Universidad Nacional de Mar del Plata

Funes 3350

7600, Mar del Plata - Prov. de Buenos Aires - Argentina

Endereço Eletrônico: pigliamelina@gmail.com

Elisa Pastoriza

CEHIS-INHUS, CONICET

Facultad de Humanidades, Universidad Nacional de Mar del Plata

Funes 3350

7600, Mar del Plata - Prov. de Buenos Aires - Argentina

Endereço Eletrônico: elisapastoriza@gmail.com 